\title{
ATRIBUTOS FÍSICOS DE UM CAMBISSOLO CULTIVADO E TRATADO COM BIOFERTILIZANTE NA CHAPADA DO APODI, CEARÁ
}

\author{
Thiago Leite de Alencar(1), Arilene Franklin Chaves(1), Carlos Levi Anastácio dos Santos(1), \\ Raimundo Nonato de Assis Júnior(2) e Jaedson Cláudio Anunciato Mota(2)*
}

(1) Universidade Federal do Ceará, Departamento de Ciências do Solo, Programa de Pós-graduação em Agronomia - Solos e Nutrição de Plantas, Fortaleza, Ceará, Brasil.

(2) Universidade Federal do Ceará, Departamento de Ciências do Solo, Fortaleza, Ceará, Brasil.

* Autor correspondente.

E-mail: jaedson.mota@ufc.br

\section{RESUMO}

O conhecimento sobre as alterações físicas e qualidade do solo é importante para o direcionamento adequado das estratégias de manejo a serem utilizadas quando da exploração do solo por cultivos agrícolas. Este trabalho teve como objetivo avaliar os efeitos do cultivo e da aplicação de um biofertilizante, obtido a partir de esterco bovino, sobre a qualidade física de um Cambissolo cultivado com Ficus carica L., irrigado por sistema de gotejamento. Para fins de avaliação da qualidade física, foram contempladas cinco situações de solo: sob cultivo de figo sem aplicação do biofertilizante (testemunha); com aplicação de 20, 40 e 60 \% do biofertilizante na lâmina de irrigação; e mata nativa secundária (testemunha adicional), até a profundidade de $0,3 \mathrm{~m}$, nas camadas de 0,0-0,1, 0,1-0,2; e 0,2-0,3 m, com quatro repetições. Nessas camadas, foram coletadas amostras de solo com estrutura deformada e indeformada para realizar análises físicas, como granulometria, argila dispersa em água, carbono orgânico, densidade das partículas e do solo, resistência do solo à penetração e curva característica de água no solo. $O$ cultivo do solo nas condições descritas nesta pesquisa, como preparo do solo por aração e gradagem, uso de irrigação e todos os tratos culturais necessários à condução da cultura de figo, não piora a qualidade física do solo em nenhuma das camadas avaliadas. A aplicação de biofertilizante melhora a qualidade física do solo, particularmente no tocante à retenção de água em decorrência do aumento da microporosidade.

Palavras-chave: degradação física do solo, matéria orgânica, cultura do figo. 


\title{
ABSTRACT: PHYSICAL PROPERTIES OF A CULTIVATED CAMBISOL TREATED WITH BIOFERTILIZER IN THE APODI PLATEAU, CEARÁ, BRAZIL
}

\begin{abstract}
Knowledge of soil physical changes and soil quality is important for creating adequate management strategies to be adopted for soil under crop production. The aim of this study was to evaluate the effects of cultivation and application of biofertilizer (obtained from cattle manure) on the physical quality of a Cambisol planted to Ficus carica L. with a drip irrigation system and to verify the efficiency of indicators in assessing changes in its physical properties. In order to evaluate physical quality, five soil scenarios were analyzed: soil under fig cultivation without application of biofertilizer (control), soil with application of 20,40 , and $60 \%$ of the biofertilizer through irrigation, and soil from secondary native forest (additional control). Analyses were made in the 0.0-0.1, 0.1-0.2, and 0.2-0.3 m layers, with four replicates. In these layers, disturbed and undisturbed soil samples were taken for physical analyses (particle size distribution, dispersed clay, organic carbon, particle density, soil bulk density, resistance to penetration, and soil water retention curve). Soil cultivation under the conditions described in this study (soil tillage with moldboard plow and disking, use of irrigation, and all crop practices needed to grow the fig crop) did not worsen soil physical quality in any of the layers evaluated. The application of biofertilizer improves the quality of soil physical properties, especially water retention, due to the increase in microporosity.
\end{abstract}

Keywords: physical soil degradation, organic matter, fig crop.

\section{INTRODUÇÃO}

A fruticultura é uma das atividades agrícolas relevantes para a economia do Brasil, visto que o país apresenta condições ambientais favoráveis para produzir frutas de excelente qualidade. No semiárido da Região Nordeste, a Chapada do Apodi é um polo promissor de fruticultura, tendo em vista as condições adequadas de clima e topografia, além da disponibilidade de recursos hídricos que viabilizam a técnica da irrigação.

É fato que a corrida pelo aumento da produção de frutos na Chapada do Apodi modificou o uso do solo, onde matas nativas foram removidas e substituídas por áreas agrícolas, com demasiado uso do recurso solo. Como resultado, tem-se, em tese, a degradação dos atributos físicos, químicos e biológicos, causando grandes perdas da qualidade do solo.

A aplicação de biofertilizante, produto resultante da biodigestão de resíduos orgânicos, apesar de sua função primária em fornecer nutrientes, tem sido uma das alternativas utilizadas para mitigar os efeitos da degradação do solo, uma vez que a matéria orgânica atua como agente cimentante entre as partículas, aumenta a capacidade de troca de cátions, disponibilizando mais nutrientes às plantas, e serve como fonte de alimento para a biota do solo.

Literaturas relacionadas à qualidade do solo tiveram importância crescente nos últimos anos (Wilson e Maliszewska-Kordybach, 2000; Dexter, 2004; Silva et al., 2014), destacando-se a preocupação com a sua manutenção e, ou, melhoria. Dessa forma, a qualidade do solo tem sido monitorada constantemente por meio da quantificação de alterações nos seus atributos decorrentes de sistemas de usos e manejos inadequados (Neves et al., 2007).
Os indicadores de qualidade do solo são necessários para monitorar mudanças e determinar tendências de melhoria ou deterioração da qualidade do solo em diversos ecossistemas (Arshad e Martin, 2002). Os principais atributos físicos considerados adequados para avaliar a qualidade física do solo estão relacionados com o conteúdo de água no solo e o oxigênio disponível para o desenvolvimento de plantas e temperatura, dentre os quais se destacam: porosidade, distribuição de tamanho de poros e resistência do solo à penetração (Campos et al., 1995; Ingaramo, 2003; Pedrotti e Mello Júnior, 2009).

Nesse contexto, o trabalho partiu das seguintes hipóteses: o cultivo, por degradar as propriedades do solo, piora sua qualidade em relação ao solo sob vegetação natural; e a aplicação de biofertilizante, que contém matéria orgânica, em solo sob cultivo, por atuar como agente cimentante entre as partículas, promove a melhoria de seus atributos físicos em relação ao solo sem aplicação de biofertilizante e sob vegetação natural. Portanto, objetivou-se avaliar os efeitos do cultivo e da aplicação de um biofertilizante, obtido a partir de esterco bovino, sobre a qualidade física de um Cambissolo cultivado com Ficus carica L., irrigado por sistema de gotejamento

\section{MATERIAL E MÉTODOS}

A área estudada está localizada na Chapada do Apodi, na Unidade de Ensino, Pesquisa e Extensão - UEPE, uma das unidades físicas do Instituto Federal de Educação, Ciência e Tecnologia (IFCE - Campus Limoeiro do Norte), situada no município de Limoeiro do Norte, Ceará, a uma altitude de $145 \mathrm{~m}$. A área experimental, cultivada 
com figo, tem em seu centro as coordenadas geográficas $5^{\circ} 10^{\prime} 57,64$ " S e $38^{\circ} 0$ ' 45,97” O. A mata secundária tomada como referência está localizada a $400 \mathrm{~m}$ da área cultivada. O solo de ambos os locais é um Cambissolo originado do calcário da Formação Jandaíra (Brasil, 1973).

O experimento com a aplicação de biofertilizante na cultura do figo foi conduzido no campo e teve início em outubro de 2010. O biofertilizante aplicado no solo foi produzido por meio de processo anaeróbico, em recipiente plástico $(200 \mathrm{~L})$. Na tampa, foi adaptada uma mangueira com a outra extremidade mergulhada num recipiente com água na altura de $20 \mathrm{~cm}$, para a saída de gases. A proporção utilizada para produção do biofertilizante foi de $50 \%$ (v/v) da fermentação do esterco bovino fresco e água, por um período de 30 dias.

As dosagens do biofertilizante foram formuladas com as seguintes proporções: T0: 0:5 - $0 \%$ de biofertilizante e $100 \%$ de água; T1: 1:4 - $20 \%$ de biofertilizante e $80 \%$ de água; T2: $2: 3$ - $40 \%$ de biofertilizante e $60 \%$ de água; e T3: 3:2 - $60 \%$ de biofertilizante e $40 \%$ de água. De acordo com essas concentrações, as proporções de água e biofertilizante para formar a solução a ser aplicada por planta foram as seguintes: T0 - sem biofertilizante e $3 \mathrm{~L}$ de água, T1 - 0,6 L de biofertilizante e 2,4 L de água, T2 - 1,2 L de biofertilizante e 1,8 L de água, e T3 - 1,8 L de biofertilizante e 1,2 L de água.

O biofertilizante foi aplicado ao solo de outubro de 2010 a agosto de 2012, totalizando 23 meses, quatro ciclos da cultura, 46 aplicações e $138 \mathrm{~L}$ da solução aplicados ao solo por planta. Amostras do biofertilizante foram analisadas no Laboratório de Solo, Água e Tecidos Vegetais (LABSAT) do IFCE, para caracterização química (Quadro 1).

Para fins de avaliação da qualidade física do solo, foram coletadas amostras com estruturas preservada e não preservada, em duas condições de manejo (solo sob plantio de figo com aplicação de doses de biofertilizante e solo sob mata secundária), nas camadas de $0,0-0,1 ; 0,1-0,2$; e 0,2-0,3 m, selecionadas de modo a abranger todo o volume de solo explorado pelo sistema radicular efetivo da cultura do figo. As coletas foram feitas com quatro repetições.
As amostras com estrutura preservada foram coletadas em anéis de aço, com dimensões de $0,05 \mathrm{~m}$ de altura por $0,05 \mathrm{~m}$ de diâmetro. Foram avaliados os seguintes atributos do solo: granulometria, argila dispersa em água (calculado o grau de floculação), carbono orgânico, densidade das partículas e do solo, resistência do solo à penetração e curva característica de água no solo. Na granulometria, a argila foi determinada pelo método da pipeta; a areia, por tamisação; e silte, por diferença a partir das frações argila e areia (Gee e Bauder, 1986). A determinação da argila dispersa em água seguiu o mesmo procedimento adotado na análise granulométrica, distinguindo-se daquele apenas por não utilizar o dispersante químico. O grau de floculação foi obtido pela equação: GF $(\%)=[($ argila total - argila dispersa em água)/argila total] $\times 100$.

$\mathrm{O}$ carbono orgânico ( $\mathrm{CO})$ foi determinado a partir da oxidação da matéria orgânica via úmida com dicromato de potássio, em presença de $\mathrm{H}_{2} \mathrm{SO}_{4}$ e aquecimento externo, titulando-se o excesso de dicromato com sulfato ferroso amoniacal (Yeomans e Bremner, 1988). A densidade das partículas $\left(\rho_{p}\right)$ foi determinada pelo método do balão volumétrico (Blake e Hartge, 1986a); e a densidade do solo $\left(\rho_{s}\right)$, a partir de amostras com estrutura preservada, coletadas em cilindros de volume conhecido e secas a $105{ }^{\circ} \mathrm{C}$ até massa constante (Blake e Hartge, 1986b). A porosidade do solo foi obtida pela equação $\alpha=\left[1-\left(\rho_{s} / \rho_{p}\right)\right]$, sendo $\alpha$ a porosidade $\left(\mathrm{m}^{3} \mathrm{~m}^{-3}\right)$ e $\rho_{p}$ e $\rho_{s}$, em $\mathrm{kg} \mathrm{dm}^{-3}$.

A resistência do solo à penetração foi definida em amostras com estrutura indeformada, com teor de água correspondente a uma tensão de $10 \mathrm{kPa}$ (Silva et al., 1994). Para tanto, se utilizou um penetrômetro eletrônico estático de laboratório, equipado com atuador linear de célula de carga de $20 \mathrm{kgf}$, haste com cone de $0,4 \mathrm{~cm}$ de diâmetro de base e ângulo de $60^{\circ}$ e área de $12,566 \mathrm{~mm}^{2}$, com velocidade de penetração de $1 \mathrm{~cm} \mathrm{~min}{ }^{-1}$, registro de uma leitura por segundo, acoplado a um microcomputador para aquisição dos dados por software próprio do equipamento, conforme descrito por Tormena et al. (1998). O procedimento compreendeu três repetições por amostra, sendo 180 leituras por repetição, totalizando 540 leituras em cada amostra, desconsiderando-se o primeiro

Quadro 1. Características químicas do biofertilizante puro e das doses estimadas, após diluído em água, nas diferentes proporções

\begin{tabular}{|c|c|c|c|c|c|c|c|c|c|c|c|c|c|c|c|c|}
\hline Am & $\mathbf{N}$ & $\mathbf{P}$ & $\mathbf{K}$ & $\mathbf{C a}$ & $\mathrm{Mg}$ & $\mathrm{S}$ & $\mathrm{Fe}$ & $\mathbf{Z n}$ & $\mathbf{C u}$ & Mn & $\mathbf{B}$ & $\mathrm{Na}$ & $\mathbf{C E}$ & $\mathrm{C}$ & $\mathrm{C} / \mathrm{N}$ & $\mathrm{pH}$ \\
\hline & \multicolumn{6}{|c|}{$\mathrm{g} \mathrm{L}^{-1}$} & \multicolumn{6}{|c|}{$\mathrm{mg} \mathrm{L}^{-1}$} & $\mathrm{dS} \mathrm{m}^{-1}$ & $\%$ & & \\
\hline Puro (100\%) & 0,78 & 0,73 & 1,19 & 0,59 & 0,28 & 0,21 & 73,04 & 5,88 & 2,04 & 9,32 & 1,62 & 175 & 7,05 & 1,080 & 13,8 & 7,78 \\
\hline $20 \%$ & 0,16 & 0,15 & 0,25 & 0,12 & 0,06 & 0,06 & 14,60 & 1,17 & 0,40 & 1,86 & 0,32 & 35 & 1,41 & 0,216 & 13,5 & 8,05 \\
\hline $40 \%$ & 0,31 & 0,29 & 0,49 & 0,24 & 0,11 & 0,08 & 29,21 & 2,35 & 0,82 & 3,72 & 0,48 & 70 & 2,82 & 0,432 & 13,9 & 8,29 \\
\hline $60 \%$ & 0,47 & 0,44 & 0,68 & 0,35 & 0,17 & 0,13 & 43,82 & 3,52 & 1,22 & 5,59 & 0,97 & 105 & 4,23 & 0,648 & 13,8 & 8,14 \\
\hline
\end{tabular}

Fonte: Silva (2012). 
e o último centímetro da amostra de solo. A resistência à penetração foi representada pela média das 540 leituras.

A curva característica de água no solo foi obtida nas amostras com estrutura indeformada. No procedimento, o conteúdo de água na saturação foi considerado igual à porosidade do solo; para os pontos de baixas tensões $(0,2,4,6,8$ e $10 \mathrm{kPa})$, o funil de Haines foi utilizado para estabelecer o equilíbrio entre a tensão aplicada e o conteúdo de água no solo. Para os demais pontos (33, 100, 700 e $1.500 \mathrm{kPa}$ ), o equilíbrio foi obtido em extrator de placa porosa de Richards (Klute, 1986). Obtidos os valores de umidade do solo em todos os pontos de tensão, foi feito o ajuste dos dados de acordo com o modelo matemático proposto por van Genuchten (1980), a partir da equação 1:

$$
\theta=\theta_{r}+\frac{\theta_{s}-\theta_{r}}{\left[1+\left(\alpha\left|\varphi_{m}\right|\right)^{n}\right]^{m}}
$$

Eq. 1

em que $\theta$ corresponde ao conteúdo de água $\left(\mathrm{m}^{3} \mathrm{~m}^{-3}\right) ; \theta r$ e $\theta s$ são, respectivamente, os teores de água residual e de saturação $\left(\mathrm{m}^{3} \mathrm{~m}^{-3}\right) ; \varphi m$ é o potencial mátrico da água no solo $(\mathrm{kPa})$; a é um escalonador do $\varphi m$; e $m$ e $n$ são parâmetros de ajuste do modelo relacionados ao formato da curva. Os dados foram ajustados com o auxílio do programa Table Curve 2D, versão trial 5.01 (Table Curve, 2014), sendo as variáveis $\theta s$ e $\theta r$ fixadas com valores, respectivamente, de conteúdo de água no solo correspondente à saturação e tensão de $1.500 \mathrm{kPa}$, ambos mensurados em laboratório. $\mathrm{O}$ ajuste dos parâmetros a, $m$ e $n$ seguiu o método iterativo de Newton-Raphson, sem dependência do parâmetro $m$ com o $n$ (Dourado Neto et al., 2001).

Os dados experimentais foram analisados em delineamento inteiramente casualizado com cinco situações de solo (sob cultivo de figo com aplicação de $20 \%$; $40 \%$; $60 \%$ do biofertilizante na lâmina de irrigação; uma testemunha sem aplicação do biofertilizante; e um tratamento adicional - solo com mata). Foi aplicado o teste de Kolmogorov-Smirnov a $5 \%$ para verificar a normalidade dos dados. Como o experimento continha duas testemunhas, uma como referência à aplicação de biofertilizante e outra ao cultivo do solo, foi realizada a análise de variância por meio do teste $\mathrm{F}$, com a comparação entre as médias dos demais tratamentos em relação à situação de solo sob mata secundária pelo teste de Dunnett a $5 \%$, considerando a configuração de cinco tratamentos e quatro repetições.

Foram aplicadas técnicas multivariadas de análise de dados, com a finalidade de evidenciar a interação entre os atributos físicos do solo de forma simultânea. Os atributos considerados foram: areia, silte, argila, densidade do solo, carbono orgânico, porosidade total, macroporosidade, microporosidade e resistência do solo à penetração nas camadas de 0,0-0,1; 0,1-0,2; e 0,2-0,3 m, em todas as situações de solo. O conjunto de dados, com distribuição normal, foi padronizado $\left(\mu=0 ; \sigma^{2}=1\right)$ para dar o mesmo peso a cada variável. Após esse procedimento, utilizou-se a técnica de análise por componentes principais (ACP) e análise de agrupamento (AA), utilizando o software XLSTAT, versão gratuita (XLSTAT, 2014).

À matriz de correlação dos atributos com os nove componentes, considerou-se o nível de significância de $5 \%$ para, então, selecionar os atributos com alta correlação com o componente principal em que se encontravam. Os atributos selecionados apresentaram correlação de no mínimo 0,6 em módulo, em pelo menos um dos componentes principais e, dessa forma, nenhum deles foi excluído. Para a análise de agrupamento das variáveis, utilizou-se o método de Ward, com a medida euclidiana para a distância entre os casos nos grupos.

\section{RESULTADOS E DISCUSSÃO}

Constatou-se que a textura do solo é franco-arenosa na profundidade de 0,0-0,1 m e franco-argiloarenosa nas demais profundidades para todos os tratamentos analisados (Quadro 2). Esses resultados estão associados tanto ao incremento de argila como à redução no teor de areia em profundidade, resultando em distintas classes texturais. Comportamentos semelhantes foram observados por Mota et al. (2008, 2013, 2014) ao analisarem atributos físicos também em um Cambissolo na Chapada do Apodi, CE. Os tratamentos que utilizaram sistema de irrigação apresentaram maiores quantidades de argila natural quando comparados à mata nativa. Esse resultado corrobora os encontrados por Dantas et al. (2012) e Mota et al. (2014), indicando haver forte influência da água de irrigação - provavelmente rica em sódio - na dispersão dos coloides.

Quanto ao grau de floculação das argilas (Figura 1), houve diferença entre os tratamentos sob cultivo e a testemunha da mata nativa para a camada de $0,0-0,1 \mathrm{~m}$, com a testemunha apresentando maior grau de floculação quando comparada aos demais tratamentos, seguramente em decorrência do conteúdo de material orgânico encontrado nessa camada e do não revolvimento do solo. Todos os valores observados indicaram elevado grau de dispersão, ou seja, muita da argila do solo foi facilmente mobilizada quando em contato com água, resultando, na maioria dos casos, em obstrução dos poros com consequente diminuição na permeabilidade do solo à água e ao ar. Resultados semelhantes foram constatados por Mota (2010), também na Chapada do Apodi, que associou a redução da condutividade hidráulica do solo saturado à elevada quantidade de argila dispersa em água. 
Quadro 2. Características físicas de um Cambissolo na Chapada do Apodi, CE, em diferentes sistemas de manejo

\begin{tabular}{|c|c|c|c|c|c|c|}
\hline Sistema de uso e manejo & Camada & Areia & Silte & Argila & Argila natural & Classe textural \\
\hline & $\mathrm{m}$ & & & $\mathrm{g} \mathrm{kg}^{-1}$ & & \\
\hline \multirow[t]{3}{*}{ Testemunha } & $0,0-0,1$ & 539 & 269 & 192 & 131 & Franco-arenosa \\
\hline & $0,1-0,2$ & 518 & 252 & 230 & 145 & Franco-argiloarenosa \\
\hline & $0,2-0,3$ & 466 & 254 & 280 & 184 & Franco-argiloarenosa \\
\hline \multirow[t]{3}{*}{ Biofertilizante (20\%) } & $0,0-0,1$ & 517 & 288 & 195 & 126 & Franco-arenosa \\
\hline & $0,1-0,2$ & 508 & 265 & 227 & 163 & Franco-argiloarenosa \\
\hline & $0,2-0,3$ & 460 & 271 & 269 & 187 & Franco-argiloarenosa \\
\hline \multirow[t]{3}{*}{ Biofertilizante (40\%) } & $0,0-0,1$ & 525 & 281 & 194 & 143 & Franco-arenosa \\
\hline & $0,1-0,2$ & 495 & 264 & 241 & 156 & Franco-argiloarenosa \\
\hline & $0,2-0,3$ & 475 & 250 & 275 & 188 & Franco-argiloarenosa \\
\hline \multirow[t]{3}{*}{ Biofertilizante (60 \%) } & $0,0-0,1$ & 542 & 261 & 197 & 158 & Franco-arenosa \\
\hline & $0,1-0,2$ & 488 & 244 & 268 & 152 & Franco-argiloarenosa \\
\hline & $0,2-0,3$ & 460 & 257 & 283 & 193 & Franco-argiloarenosa \\
\hline \multirow[t]{3}{*}{ Mata } & $0,0-0,1$ & 748 & 156 & 96 & 50 & Franco-arenosa \\
\hline & $0,1-0,2$ & 625 & 154 & 221 & 132 & Franco-argiloarenosa \\
\hline & $0,2-0,3$ & 507 & 168 & 325 & 186 & Franco-argiloarenosa \\
\hline
\end{tabular}

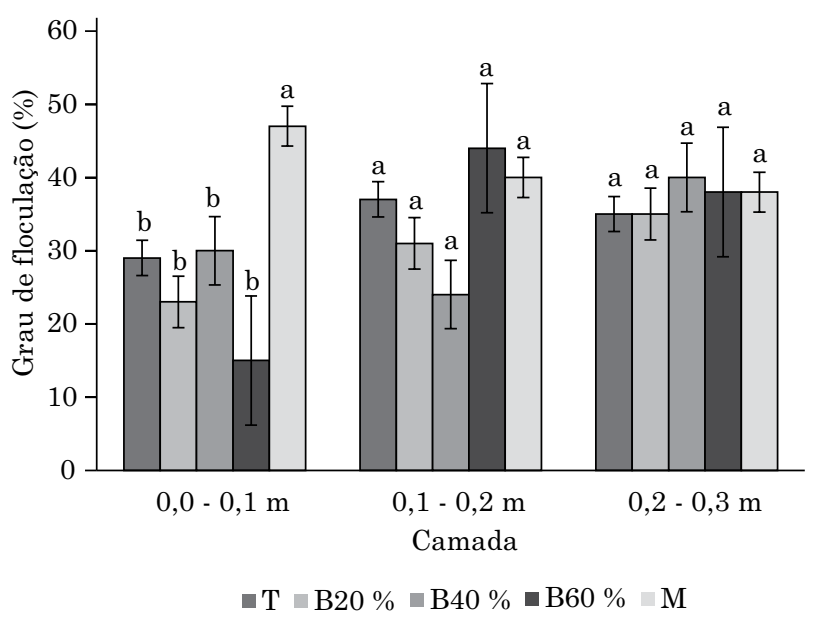

Figura 1. Grau de floculação, com os erros da média, para as áreas sob cultivo de figo e mata secundária (T - Testemunha; B20 \% - Biofertilizante $20 \%$; B40 \% -Biofertilizante $40 \%$; B60 \% - Biofertilizante $60 \%$; e M - Mata nativa). Médias seguidas pela mesma letra na camada não diferem pelo teste de Dunnett $(p \leq 0,05)$.

Vale destacar que em todos os tratamentos, exceto a testemunha, houve aporte de material orgânico via aplicação do biofertilizante, além da vegetação espontânea, fatores que concorrem para a floculação das argilas. Contudo, possíveis valores elevados do íon $\mathrm{Na}^{+}$, que atua na dispersão dos coloides do solo, oriundos do biofertilizante (Quadro 1), da água de irrigação e do próprio solo, explicam parte dos baixos valores de argila floculada. É importante salientar a natureza mineral das argilas dos Cambissolos da Chapada do Apodi, predominantemente cauliníticas (Mota et al., 2008), portanto do tipo 1:1, com menos cargas de superfície, o que as predispõe facilmente à dispersão.

A densidade de partículas não apresentou diferença entre os tratamentos sob cultivo e a situação de mata nativa em nenhuma camada analisada (Figura 2). Esse resultado deve-se ao fato de a densidade de partículas ser um atributo com pouca variação no espaço e no tempo (Ferreira, 2010) e depender da natureza mineralógica do solo (Rühlmann et al., 2006). Resultados semelhantes foram encontrados por Mota et al. (2014), estudando a qualidade física do solo sob cultivo de abacaxi irrigado na Chapada do Apodi.

É importante destacar que os valores observados encontram-se abaixo do que é frequentemente utilizado para representar todos os solos minerais, $2,65 \mathrm{~kg} \mathrm{dm}^{-3}$, considerando que na maioria dos solos de regiões tropicais o quartzo predomina em relação aos outros minerais (Skoop, 2002). Dessa forma, existem partículas no solo em estudo menos densas que o quartzo que estão contribuindo para a diminuição do valor de densidade de partículas para menos de $2,65 \mathrm{~kg} \mathrm{dm}^{-3}$.

No que se refere à densidade do solo, os valores para todos os sistemas avaliados sob cultivo nas camadas superficiais $(0,0-0,1$ e 0,1-0,2 m) não apresentaram diferença em comparação à situação de solo sob mata nativa (Figura 3), de forma semelhante aos resultados encontrados por Nogueira (2009), estudando a influência da aplicação de biofertilizante em propriedades físicas de um Cambissolo na 


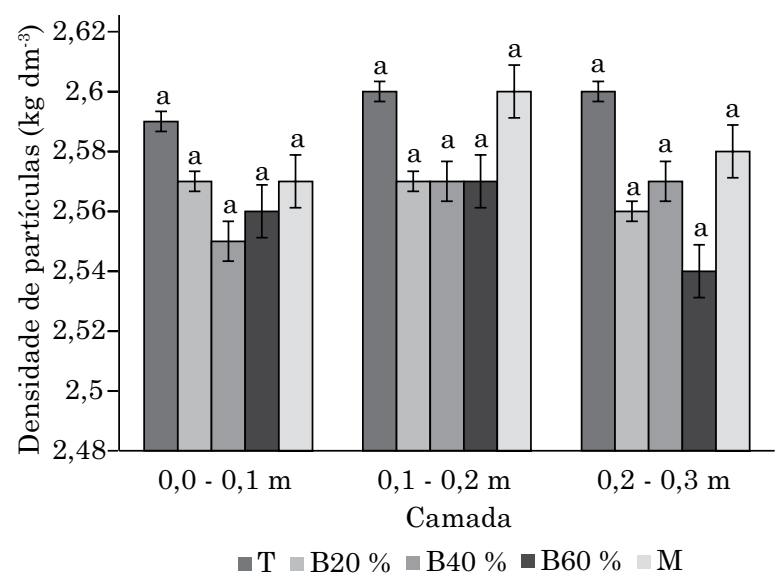

Figura 2.Densidadede partículas, comos erros da média, para as áreas sob cultivo de figo e mata secundária (T - Testemunha; B20 \% - Biofertilizante $20 \%$; B40 \% - Biofertilizante $40 \%$; B60 \% - Biofertilizante $60 \%$; e M - Mata nativa). Médias seguidas pela mesma letra na camada não diferem pelo teste de Dunnett $(p \leq 0,05)$.

Chapada do Apodi. Ao comparar os sistemas na camada de 0,2-0,3 m, a aplicação de biofertilizante $60 \%$ possibilitou menor valor de densidade do solo em relação à mata. Esse resultado pode estar ligado ao maior desenvolvimento das raízes de figo nessa profundidade, pois, conforme Silva (2012), nesse mesmo experimento, quando da aplicação de biofertilizante $60 \%$, houve melhor adequação nutricional à planta, com melhor desenvolvimento foliar e consequente aumento de produtividade. Para Correchel et al. (1999), maior volume de raízes contribui para melhorar a condição estrutural do solo com consequente redução de sua densidade.

Os valores de densidade do solo variaram de 1,43 a $1,58 \mathrm{~kg} \mathrm{dm}^{-3} \mathrm{em}$ todas as profundidades analisadas, valores acima do estabelecido pela USDA (1999) (menor que 1,40 $\mathrm{kg} \mathrm{dm}^{-3}$ ) para as texturas encontradas. Porém, os estes não ultrapassaram o valor de densidade do solo que restringe o crescimento das raízes das culturas, cujo valor está acima de $1,75 \mathrm{~kg} \mathrm{dm}^{-3}$ para a situação em análise. Resultados semelhantes foram encontrados por Mota et al. (2008), Mota (2010), e Mota et al. (2014), em Cambissolos na mesma região.

Quanto ao teor de CO no solo, os sistemas com e sem aplicação do biofertilizante não diferiram da mata nativa (Figura 4) pelo fato de o biofertilizante aplicado ter baixa quantidade de $\mathrm{C}$ na sua composição (Quadro 1), em razão das perdas por digestão e da liberação de $\mathrm{CO}_{2}$ e $\mathrm{CH}_{4}$ no processo de biodigestão (Medeiros e Lopes, 2006). Também, uma causa para os resultados não diferirem está relacionada à baixa relação $\mathrm{C}: \mathrm{N}$ do biofertilizante (Quadro 1), que favorece a rápida mineralização da matéria orgânica adicionada ao solo (Cas, 2009); além

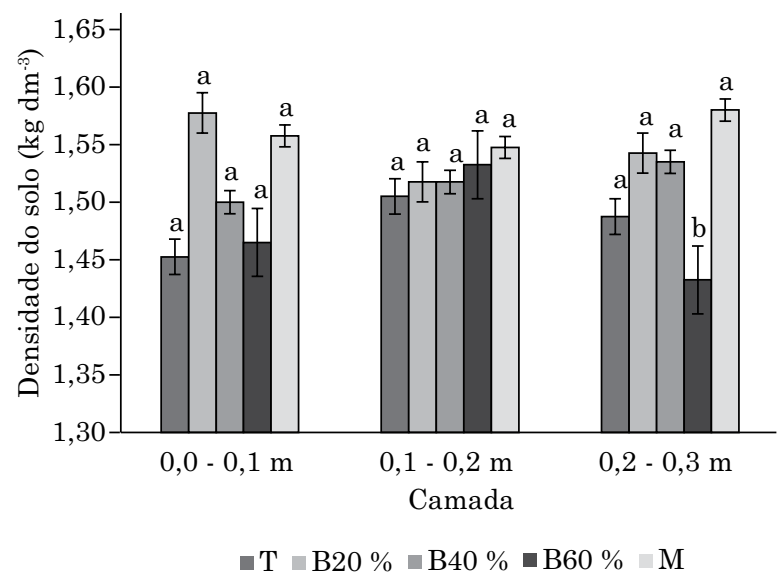

Figura 3. Densidade do solo, com os erros da média, para as áreas sob cultivo de figo e mata secundária (T - Testemunha; B20 \% - Biofertilizante $20 \%$; B40 \% - Biofertilizante $40 \%$; B60 \% - Biofertilizante $60 \%$; e M - Mata nativa). Médias seguidas pela mesma letra na camada não diferem pelo teste de Dunnett $(p \leq 0,05)$.

disso, as condições ambientais no sistema com mata nativa, constituído predominantemente por arbustos hiperxerófilos, não favorecem grande aporte de biomassa vegetal ao solo (Mota, 2010), em comparação com outros biomas brasileiros. Resultados encontrados por Nogueira (2009) corroboram os aqui observados. Costa et al. (2010) citaram que a produção de serapilheira no bioma Caatinga varia, em média, de 1.500 a $3.500 \mathrm{~kg} \mathrm{~h}^{-1} \mathrm{ano}^{-1}$, tanto em florestas arbóreas quanto em arbustivas, dependendo das características morfológicas e fisiológicas comuns das plantas que constituem o bioma.

Os valores de resistência à penetração na umidade correspondente à capacidade de campo não diferiram entre os sistemas cultivados nas diferentes profundidades e a mata nativa (Figura 5). A aplicação do biofertilizante não produziu efeitos sobre a resistência à penetração, o que também foi encontrado por Dias et al. (2011) ao estudarem essa variável em um solo de textura arenosa tratado com biofertilizante bovino. Observou-se que tanto o solo da mata nativa quanto o cultivado sem adição de biofertilizante, naturalmente, já apresentavam baixa resistência à penetração, fato que pode ter inibido o efeito benéfico do biofertilizante. Nesse caso, resta a perspectiva de outros estudos para averiguar o efeito de biofertilizante em situações em que o solo já apresente elevada resistência à penetração. No caso do trabalho de Dias et al. (2011), de igual modo, os possíveis efeitos benéficos do biofertilizante não foram comprovados porque, na maioria dos casos, solos arenosos, por apresentarem maior macroporosidade, não oferecem elevada resistência à penetração de raízes. 


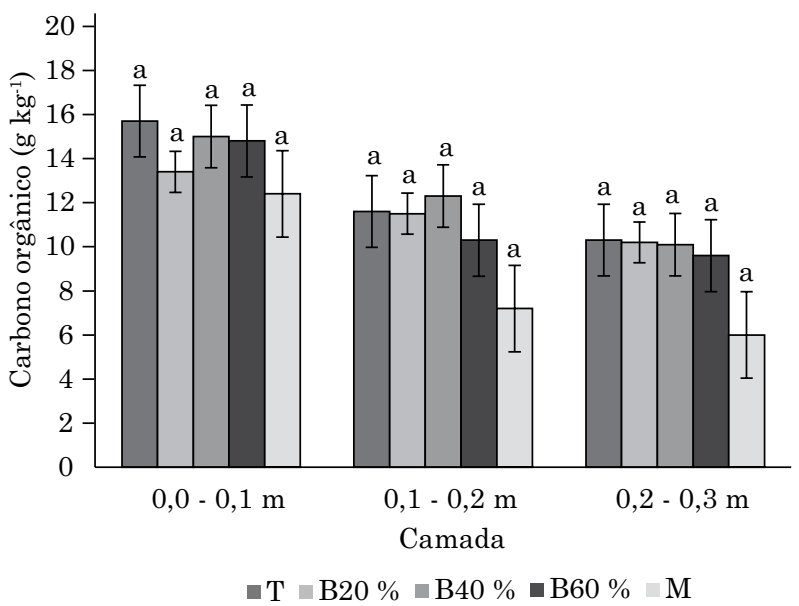

Figura 4. Teores de carbono orgânico, com os erros da média, para as áreas sob cultivo de figo e mata secundária ( $T$ - Testemunha; B20 \% - Biofertilizante $20 \%$; B40 \% - Biofertilizante $40 \%$; B60 \% - Biofertilizante $60 \%$; e M-Mata nativa). Médias seguidas pela mesma letra na camada não diferem pelo teste de Dunnett $(p \leq 0,05)$.

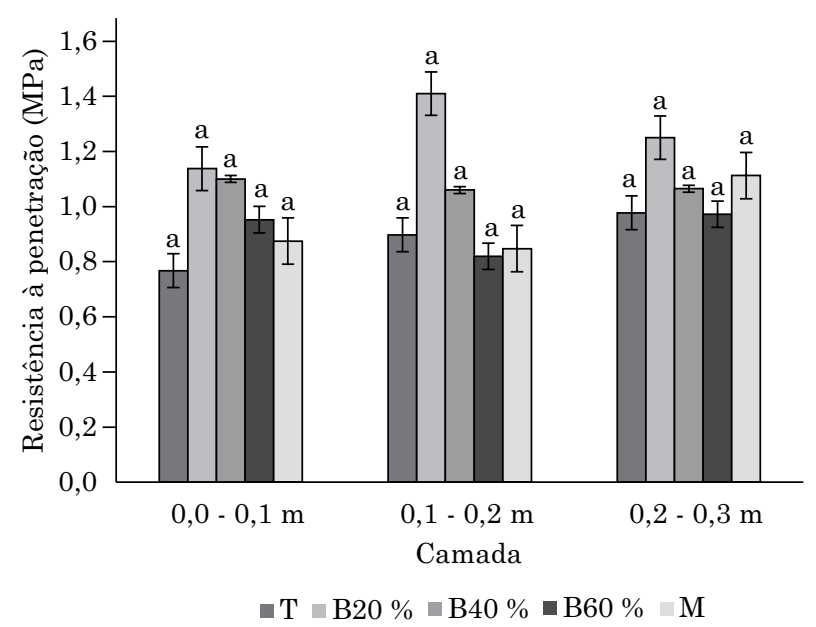

Figura 5. Resistência do solo à penetração, com os erros da média, para as áreas sob cultivo de figo e mata secundária ( $\mathrm{T}$ - Testemunha; B20\% - Biofertilizante $20 \%$; B40 \% - Biofertilizante $40 \%$; B60 \% - Biofertilizante $60 \%$; e M-Mata nativa). Médias seguidas pela mesma letra na camada não diferem pelo teste de Dunnett $(p \leq 0,05)$.

A resistência à penetração variou de 0,77 a 1,41 MPa e, portanto, não limitou o crescimento das raízes das plantas, uma vez que o valor considerado crítico, $2 \mathrm{MPa}$ (Silva et al., 1994), não foi atingido. Dessa forma, o solo, em todos os sistemas avaliados, não apresentou problemas de resistência à penetração quando mantido na capacidade de campo, condição em que normalmente se busca mantê-lo quando sob cultivos irrigados. É importante ressaltar que, apesar do elevado teor de água na zona de solo irrigada, o que aumenta a sensibilidade à compactação do solo e, ou, acomodação natural das partículas no processo de adensamento, há o efeito benéfico dos sucessivos ciclos de molhamento e secagem do solo causado pelas alternâncias de irrigação, possibilitanto a formação de agregados estáveis e com maior porosidade entre as unidades estruturais, o que contribui para evitar a elevação da resistência do solo à penetração de raízes.

As curvas características de água no solo para os sistemas avaliados nas camadas de $0,0-0,1$; $0,1-0,2$; e $0,2-0,3 \mathrm{~m}$ estão contidas nas figuras 6 , 7 e 8 , respectivamente. Analisando-se a faixa de tensão em que, de acordo com Klein e Libardi (2002), a água está retida nos macroporos (0 a $6 \mathrm{kPa})$, os tratamentos apresentaram-se semelhantes em relação à capacidade de retenção de água.

Na figura 6, a faixa de tensão, em que, segundo Klein e Libardi (2002), a água se encontra nos microporos (6 a $1.500 \mathrm{kPa}$ ), indica que os sistemas com aplicação do biofertilizante 20,40 e $60 \%$ proporcionaram maior retenção de água, fato associado à maior quantidade de microporos (81, 74 e $78 \%$ da porosidade total - PT, respectivamente). É pertinente que sejam feitas algumas inferências a respeito do biofertilizante aplicado ao solo. Sabe-se que os biofertilizantes possuem resíduos sólidos em suspensão e, portanto, a sua aplicação no solo pode ter obstruído ou diminuído o diâmetro dos macroporos, importantes para o fluxo de gases, no longo do tempo, principalmente nas camadas mais superficiais. Para fundamentar o que se pressupõe ter ocorrido, ao final do experimento a quantidade de matéria orgânica adicionada ao solo por meio do biofertilizante 20, 40 e $60 \%$ foi de aproximadamente 0,$41 ; 0,82 ;$ e $1,24 \mathrm{~kg}$ por área disponível à planta, respectivamente, o que fez com que os tratamentos com aplicação do biofertilizante apresentassem maiores valores de microporosidade. Se a microporosidade foi aumentada, a hipótese da obstrução ou redução do diâmetro dos poros pelos resíduos orgânicos não deve ser descartada. O solo sob mata nativa apresentou menor retenção para essa faixa de tensão, por conter menos microporos (63\% da PT).

Ao se analisar a frequência acumulada de poros para os tratamentos em estudo (Figura 6), com ênfase na tensão correspondente à capacidade de campo utilizada no intervalo hídrico menos limitante (10 kPa), que, segundo Andrade e Stone (2011), é de grande importância para os processos de drenagem, a disponibilidade de água para as culturas e o manejo adequado do sistema de irrigação, observou-se que o solo sob cultivo apresentou menor volume de poros preenchidos com ar quando comparado à mata secundária. Dessa forma, ao se aplicar a tensão de $10 \mathrm{kPa}$, estavam disponíveis ao fluxo de ar entre 22 e $32 \%$ dos poros no solo cultivado, em contraste com $44 \%$ no solo sob mata nativa. 


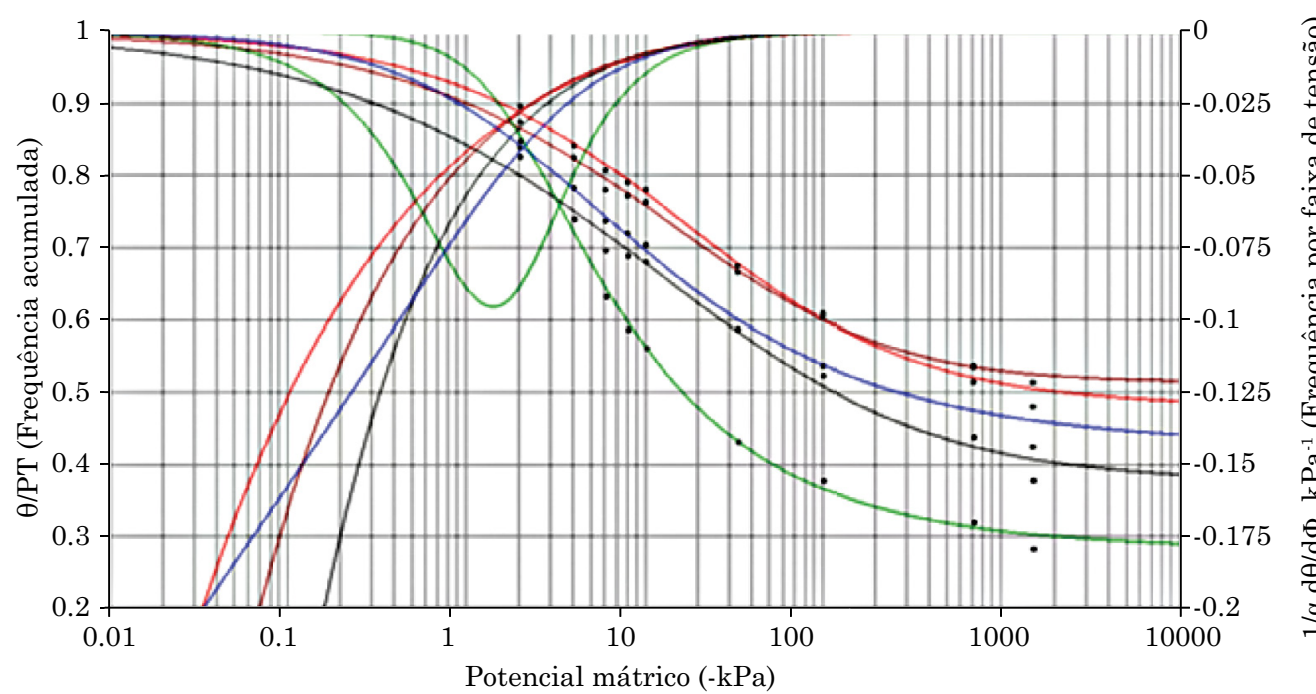

$\begin{array}{lccccccc} & \alpha & m & n & \theta s / P T & \theta r / P T & P T\left(m^{3} m^{-3}\right) & \text { Inflexão (-kPa) } \\ \text { - Testemunha } & 0,0322 & 1,5665 & 0,4598 & 1,0000 & 0,3781 & 0,4391 & 19 \\ \text { - Biofertilizante 20 \% } & 0,0540 & 1,0874 & 0,6208 & 1,0000 & 0,4804 & 0,3849 & 28 \\ \text { - Biofertilizante 40 \% } & 0,4238 & 0,5124 & 0,8372 & 1,0000 & 0,4270 & 0,4117 & 17 \\ \text { - Biofertilizante 60\% } & 0,0236 & 1,8212 & 0,5373 & 1,0000 & 0,5143 & 0,4279 & 15 \\ \text { - Mata } & 0,5886 & 0,2605 & 2,0308 & 1,0000 & 0,2832 & 0,3944 & 11\end{array}$

Figura 6. Curva característica de água no solo e curva diferencial da curva característica de água no solo para as áreas sob cultivo de figo e mata secundária na camada de 0,0-0,1 m.

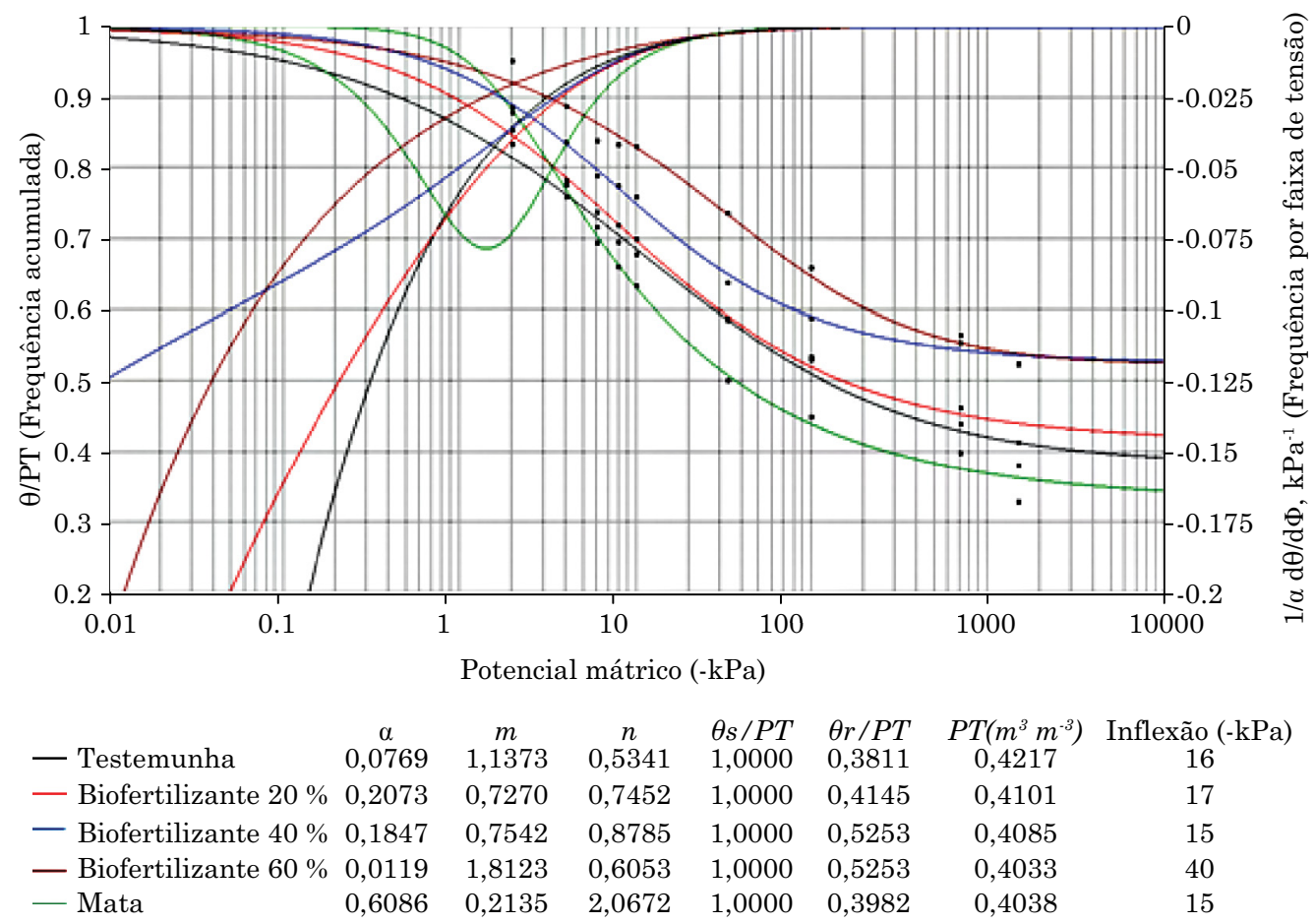

Figura 7. Curva característica de água no solo e curva diferencial da curva característica de água no solo para as áreas sob cultivo de figo e mata secundária na camada de 0,1-0,2 m. 


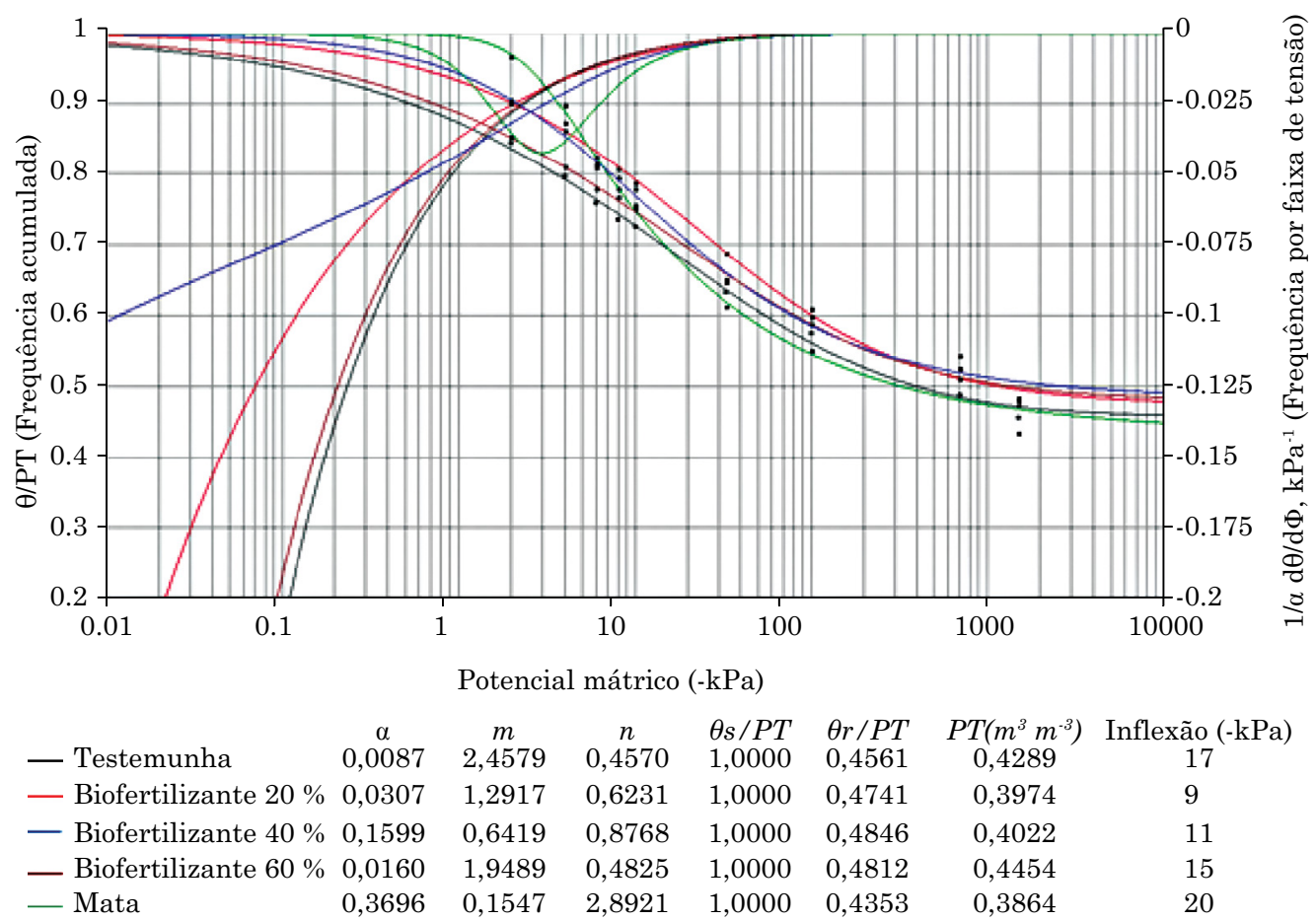

Figura 8. Curva característica de água no solo e curva diferencial da curva característica de água no solo para as áreas sob cultivo de figo e mata secundária na camada de 0,2-0,3 m.

No tocante ao ponto de inflexão, que segundo Dexter e Bird (2001) é o ponto de umidade ótima para o cultivo, ou seja, a capacidade de campo, observou-se que os valores de tensão em todos os sistemas se encontraram abaixo do valor que rotineiramente se considera para solo argiloso $-33 \mathrm{kPa}$ (Amaro Filho et al., 2008; Stumpf, 2011; Souza et al., 2013). Este resultado indicou a necessidade de se revisitar o conceito de capacidade de campo; de um lado, quanto aos valores normalmente arbitrados na literatura para distintas texturas do solo e, de outro, quanto à veracidade de que ocorre no entorno do ponto de inflexão da curva característica de água no solo, haja vista a discrepância observada nos casos em análise.

Comparando-se os pontos de inflexão, é expressiva a variação entre os tratamentos, visto que o sistema com biofertilizante $20 \%$ apresentou ponto de inflexão em potencial mátrico mais negativo, fato ocasionado possivelmente pela maior microporosidade que atua retendo mais água e, consequentemente, diminuindo a inclinação da reta tangente ao ponto de inflexão, aspecto importante para definir o índice $\mathrm{S}$ de Dexter (2004). Para corroborar esses resultados, fez-se a análise de regressão das variáveis potencial mátrico no ponto de inflexão ( $\varphi_{\mathrm{m}}$ inflexão, variável dependente) e percentagem de microporos (variável independente), para as 60 curvas características de água no solo desse experimento, obtendo-se a função $\hat{y}=67,126-0,35 \mathrm{x}$, com coeficiente de determinação $\mathrm{R}^{2}=0,58$, coeficiente angular $b \neq 0$, ambos significativos a $1 \%$. Portanto, fica evidente que o aumento na microporosidade desloca o ponto de inflexão para potenciais mátricos mais negativos.

Analisando-se a curva diferencial (Figura 6), observou-se que o poro mais frequente para os solos sob cultivo situa-se próximo à saturação, enquanto para a condição sob mata secundária encontra-se no entorno de $216 \mu \mathrm{m}$. De acordo com Hillel (2004) e Libardi (2012), a representação é de um diâmetro de poro equivalente, visto que a rede porosa do solo é complexa e irregular no aspecto morfológico e dimensional.

Ao se analisar a figura 7, na faixa de tensão de 6 a $1.500 \mathrm{kPa}$, referente à camada de $0,1-0,2 \mathrm{~m}$, observou-se situação semelhante à camada superficial, em que os tratamentos com biofertilizante 20,40 e $60 \%$ apresentaram maiores valores de microporosidade, 74,79 e $84 \%$ da PT, respectivamente. A mata apresentou menor retenção de água para a tensão em análise por possuir menor microporosidade (69 \% da PT).

Assim como na profundidade de 0,0-0,1 m, o ponto de inflexão encontrou-se também deslocado para um potencial mátrico menos negativo em todos os sistemas analisados, fato que indicou novamente a necessidade de se reverem os conceitos atribuídos à determinação da capacidade de campo em laboratório, em potenciais mátricos arbitrados, 
ou a partir da curva característica de água no solo, em seu ponto de inflexão. A área com aplicação do biofertilizante $60 \%$, por possuir maior quantidade de microporos, atingiu o ponto de inflexão em uma tensão superior às demais, fato já explicado a partir da correlação entre essas variáveis. A partir da figura 7 , ao se observar a frequência acumulada, tem-se que, para a tensão de $10 \mathrm{kPa}$, os sistemas sob cultivo apresentaram menores quantidades de poros disponíveis ao fluxo de ar, variando de 17 a $32 \%$, enquanto para a mesma tensão a mata secundária apresentou $37 \%$ de poros livres de água. $\mathrm{O}$ diâmetro do poro mais frequente para o solo com mata também foi de $216 \mu \mathrm{m}$; já para o solo sob cultivo, o poro mais frequente foi encontrado próximo à saturação, semelhante ao observado para a camada superficial.

De acordo com a figura 8, correspondente à camada de 0,2-0,3 m, é perceptível que houve redução no efeito do biofertilizante sobre a obstrução/redução do diâmetro dos poros, o que torna a retenção de água muito mais semelhante entre os tratamentos. O ponto de inflexão também continuou deslocado para mais próximo da saturação, requerendo os mesmos cuidados no tocante à determinação da capacidade de campo. Analisando a frequência acumulada na tensão de $10 \mathrm{kPa}$, observou-se diferença em relação às camadas anteriores, em que a testemunha apresentou $28 \%$ dos poros disponíveis para trocas gasosas, e os sistemas com biofertilizante e mata variaram de 21 a $24 \%$. O poro mais frequente para o solo com mata ficou em torno de $105 \mu \mathrm{m}$ de diâmetro; no solo cultivado, mais próximo à saturação, ou seja, com poro mais frequente maior em relação à mata.

Com relação à análise multivariada de dados, é importante ressaltar que essa tem a vantagem de explorar a interdependência entre as variáveis (Fidalski et al., 2007), em uma tentativa de compreender as suas relações complexas, o que não é possível por meio de métodos uni e bivariados (Hair Jr. et al., 2009). A matriz de dados para análise de componentes principais (ACP) foi composta por nove variáveis. Foram obtidos sete componentes (Quadro 3), juntamente com seus respectivos autovalores e variabilidade explicada. Os componentes principais foram escolhidos levando-se em conta o critério de Kaiser (1958), em que são selecionados autovalores acima da unidade, por indicarem informações importantes que não devem ser desconsideradas. Dessa forma, foram selecionados os componentes principais $\mathrm{CP} 1, \mathrm{CP} 2$ e CP3, por estarem de acordo com as condições exigidas. Tais componentes, unidos, explicam aproximadamente $90,88 \%$ da variância dos dados, sendo 42,55, 32,23 e 16,10 \% da variância explicada pelos componentes principais 1, 2 e 3, respectivamente (Quadro 3).
Quadro 3. Autovalores e porcentagem da variabilidade explicada por cada componente principal, em termos absoluto e acumulada

\begin{tabular}{lccc}
\hline \multirow{2}{*}{$\begin{array}{l}\text { Componente } \\
\text { principal }\end{array}$} & Autovalor & \multicolumn{2}{c}{ Variabilidade explicada } \\
\cline { 3 - 4 } & & \multicolumn{2}{c}{$\%$} \\
\hline & & $4 b s o l u t a$ & Acumulada \\
\hline & 3,830 & 32,23 & 74,55 \\
2 & 2,901 & 16,10 & 90,88 \\
3 & 1,449 & 6,95 & 97,83 \\
4 & 0,626 & 1,66 & 99,49 \\
5 & 0,150 & 0,40 & 99,89 \\
6 & 0,036 & 0,11 & 100,00 \\
7 & 0,009 & & \\
\hline
\end{tabular}

Analisando-se o CP1, as varáveis de maior importância foram areia, silte, argila, macro e microporosidade; e para o CP2, foram densidade do solo, $\mathrm{CO}$ e PT. Para o $\mathrm{CP} 3$, a resistência à penetração foi a variável que mais contribuiu com a variância dos dados (Quadro 4).

Pela figura 9a, percebe-se que as variáveis estão mais distantes do centro, enquanto na figura $9 \mathrm{~b}$ somente algumas estão distantes dele, ou seja, apenas as que apresentam boa contribuição aos componentes principais. A partir da figura 9a, que contém os componentes principais 1 e 2 , constata-se que as variáveis densidade do solo e PT, por estarem situadas em quadrantes opostos, apresentam correlação negativa, fato já esperado, porém não evidenciado nas análises univariadas. Situação semelhante foi observada para as variáveis areia e microporosidade, indicando que o aumento de uma implica diminuição da outra. A mesma interpretação deve ser dada para a correlação entre as variáveis argila e macroporosidade, demonstrando que a textura tem influência no sistema poroso do solo (Kiehl, 1979).

Ainda na figura 9a, percebe-se que os sistemas com biofertilizante $20 \%$ e mata secundária, nas camadas de 0,0-0,1 e 0,1-0,2 m, respectivamente, foram semelhantes, pois permaneceram no mesmo quadrante, e a variável que influenciou para discriminar tais sistemas foi a densidade do solo. Já para o solo sob mata secundária, os tratamentos biofertilizante 20,40 e $60 \%$, associados às camadas de $0,2-0,3 \mathrm{~m}, 0,1-0,2$ e $0,2-0,3 \mathrm{~m}, 0,1-0,2$ e $0,2-0,3 \mathrm{~m}$, 0,1-0,2 m, respectivamente, foram distinguidos pela influência da resistência à penetração e da argila, fato decorrente do incremento dessa fração por translocação no perfil de camadas analisadas.

A testemunha, na camada de 0,2-0,3 m, e o biofertilizante $60 \%(0,0-0,1$ e $0,2-0,3 \mathrm{~m})$ situaram-se em outro quadrante; portanto, sendo influenciados por outras variáveis, particularmente a PT, microporosidade e silte. Os sistemas com a testemunha (0,0-0,1 e 0,1-0,2 m) e 
Quadro 4. Correlação entre as variáveis e os componentes principais e sua respectiva contribuição para cada componente

\begin{tabular}{|c|c|c|c|c|c|c|}
\hline Variável & CP1 & CP2 & CP3 & CP1 & CP2 & CP3 \\
\hline & & & & \multicolumn{3}{|c|}{$\%$} \\
\hline Areia & $-0,984$ & $-0,007$ & $-0,014$ & 25,284 & 0,0020 & 0,0130 \\
\hline Silte & 0,661 & $-0,476$ & 0,544 & 11,402 & 7,8120 & 20,429 \\
\hline Argila & 0,797 & 0,394 & $-0,420$ & 16,591 & 5,3630 & 12,184 \\
\hline Densidade do solo & $-0,326$ & 0,878 & 0,272 & 2,7750 & 26,578 & 5,1240 \\
\hline Carbono orgânico & $-0,078$ & $-0,759$ & 0,593 & 0,1590 & 19,839 & 24,273 \\
\hline Porosidade total & 0,262 & $-0,863$ & $-0,375$ & 1,7960 & 25,647 & 9,7210 \\
\hline Macroporosidade & $-0,755$ & $-0,535$ & $-0,144$ & 14,899 & 9,8770 & 1,4270 \\
\hline Microporosidade & 0,959 & $-0,087$ & $-0,128$ & 24,008 & 0,2610 & 1,1370 \\
\hline Resistência à penetração & 0,344 & 0,366 & 0,610 & 3,0870 & 4,6220 & 25,693 \\
\hline
\end{tabular}
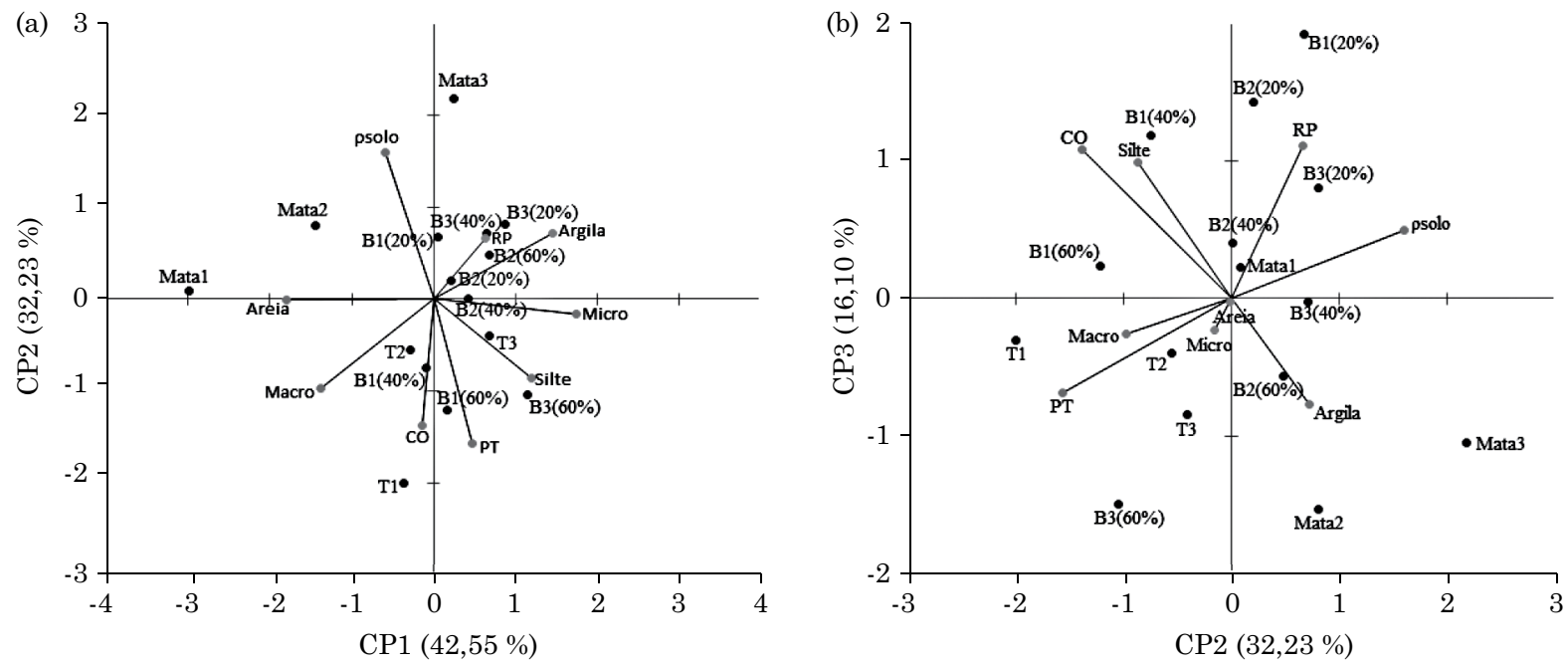

Figura 9. Dispersão dos atributos físicos para as áreas sob cultivo de figo e mata secundária nas camadas de $0,0-0,1 ; 0,1-0,2$ e $0,2-0,3 \mathrm{~m}$, sendo (a) para componentes principais 1 e 2 , (b) para componentes principais 2 e 3. osolo: densidade do solo; PT: porosidade total; Micro: microporos; Macro: macroporos; RP: resistência do solo à penetração; T1, T2, T3 correspondem ao tratamento testemunha (cultivado, porém sem adição de biofertilizante), B1 (20\%), B2 (20\%), B3 (20 \%) ao solo cultivado, com adição de biofertilizante $20 \%$, B1 (40 \%), B2 (40 \%), B3 (40 \%) ao com biofertilizante $40 \%$, B1 (60 \%), B2 (60 \%), B3 $(60 \%)$ ao com biofertilizante $60 \%$ e Mata1, Mata2, Mata3 à mata secundária, todos, respectivamente, às camadas de $0,0-0,1 ; 0,1-0,2$ e $0,2-0,3 \mathrm{~m}$.

biofertilizante $40 \%(0,0-0,1 \mathrm{~m})$ sofreram influência da macroporosidade e do CO.

$\mathrm{Na}$ figura $9 \mathrm{~b}$, que trata dos componentes principais 2 e 3 , observa-se que as variáveis densidade do solo e macroporosidade apresentaram correlação negativa por estarem em quadrantes opostos, evidenciando que a densidade do solo tem ampla influência no fluxo de água e ar no solo. Vale-se destacar que a camada superficial dos solos com os tratamentos biofertilizante 40 e $60 \%$, que foram semelhantes, foi discriminada pelas variáveis $\mathrm{CO}$ e silte, em decorrência do maior aporte de material orgânico em superfície.
Observando-se o dendrograma, foi possível constatar a formação de quatro grupos (Figura 10). O primeiro grupo foi formado pelas camadas superficial e de 0,1-0,2 $\mathrm{m}$ da mata secundária. Os tratamentos com biofertilizante $40 \%(0,0-0,1 \mathrm{~m}), 60 \%(0,0-0,1$ e $0,2-0,3 \mathrm{~m})$ e testemunha em todas as camadas formaram outro grupo. A camada subsuperficial do sistema com mata secundária ficou isolada e, finalmente, outro grupo foi constituído pelos tratamentos com biofertilizante $20 \%$ $(0,0-0,1 ; 0,1-0,2$ e $0,2-0,3 \mathrm{~m}), 40 \%(0,1-0,2$ e $0,2-0,3 \mathrm{~m})$ e $60 \%(0,1-0,2 \mathrm{~m})$. Dessa forma, ficou evidenciada a discriminação dos sistemas cultivados em relação à da mata secundária. 


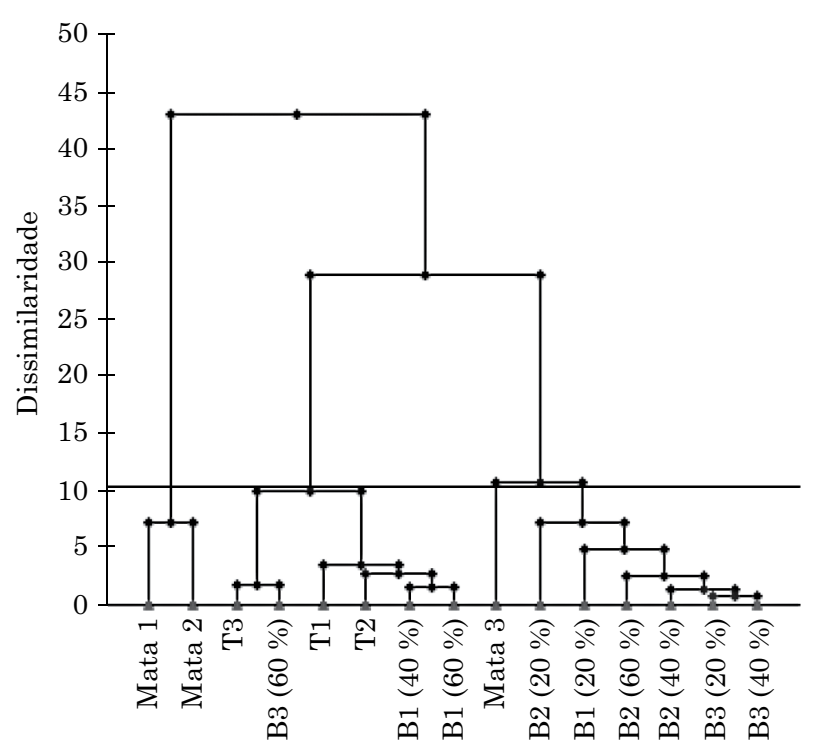

Figura 10. Dendrograma representando a dissimilaridade entre o grupo da testemunha e o do cultivo de figo. T1, T2, T3 correspondem ao sistema com a testemunha, B1(20\%), B2 (20\%), B3 (20\%) ao sistema com biofertilizante $20 \%$, B1(40 \%), B2 (40 \%), B3 (40 \%) ao com biofertilizante $40 \%$, B1(60 \%), B2 (60\%), B3 (60\%) ao com biofertilizante $60 \%$ e M1, M2, M3 à mata secundária, todos, respectivamente, às camadas de 0,0-0,1, 0,1-0,2 e 0,2-0,3 m.

\section{CONCLUSÕES}

O cultivo do solo nas condições descritas nesta pesquisa (preparo do solo por aração e gradagem, uso de irrigação e todos os tratos culturais necessários à condução da cultura de figo) não piora a qualidade física do solo em nenhuma das camadas avaliadas.

A aplicação de biofertilizante melhora a qualidade física do solo, particularmente no tocante à retenção de água em decorrência do aumento da microporosidade. É prudente que se faça monitoramento periódico da porosidade de solos que recebem a aplicação de biofertilizante, pois há a possibilidade da redução do tamanho dos poros maiores e a obstrução de microporos.

\section{AGRADECIMENTOS}

Ao Instituto Federal de Educação, Ciência e Tecnologia (IFCE - Campus Limoeiro do Norte), pelo apoio à realização do experimento; à Coordenação de Aperfeiçoamento de Pessoal de Ensino Superior (CAPES), pela concessão da bolsa durante o período de estudo; e à Fundação Cearense de Apoio ao Desenvolvimento Científico e Tecnológico (FUNCAP), pelo apoio financeiro à pesquisa.

\section{REFERÊNCIAS}

Amaro Filho J, Assis Júnior RN, Mota JCA. Física do solo: Conceitos e aplicações. Fortaleza: Imprensa Universitária; 2008. v.1.

Andrade RS, Stone LF. Estimativa da umidade na capacidade de campo em solos sob Cerrado. R Bras Eng Agríc Amb. 2011;15:111-6.

Arshad MA, Martin S. Identifying critical limits for soil quality indicators in agro-ecosystems. Agric Ecosyst Environ. 2002;88:153-60.

Blake GR, Hartge KH. Bulk density. In: Klute A, editor. Methods of soil analysis. $2^{\text {nd }}$.ed. Madison: American Society of Agronomy, Soil Science Society of America; 1986a. Pt.1. p.363-75 (Agronomy monography, 9).

Blake GR, Hartge KH. Particle density. In: Klute A, editor. Methods of soil analysis. $2^{\text {nd }}$.ed. Madison: American Society of Agronomy, Soil Science Society of America; 1986b. Pt.1. p.377-82. (Agronomy monography, 9).

Brasil. Divisão de Pesquisa Pedológica. Levantamento exploratório: Reconhecimento de solos do Estado do Ceará. Recife: 1973. v.1. (DNPEA, Boletim Técnico, 28; Sudene. Série Pedologia, 16).

Campos BC, Reinert DJ, Nicolodi R, Ruedell J, Petrere C. Estabilidade estrutural de um Latossolo Vermelho-Escuro distrófico após sete anos de rotação de culturas e sistemas de manejo. R Bras Ci Solo. 1995;19:121-6.

Cas VLS. Mineralização do carbono e do nitrogênio no solo com o uso do lodo de esgoto e palha de aveia [dissertação]. Santa Maria: Universidade Federal de Santa Maria; 2009.

Correchel V, Silva AP, Tormena CA. Influência da posição relativa à linha de cultivo sobre a densidade do solo em dois sistemas de manejo do solo. R Bras Ci Solo. 1999;23:165-73.

Costa CCA, Camacho RGV, Macedo ID, Silva PCM. Análise comparativa da produção de serapilheira em fragmentos arbóreos e arbustivos em área de Caatinga na Flona de Açu-RN. R Árvore. 2010;34:259-65.

Dantas JDAN, Oliveira TS, Mendonca ES, Assis CP. Qualidade de solo sob diferentes usos e manejos no Perímetro Irrigado Jaguaribe/Apodi, CE. R Bras Eng Agríc Amb. 2012;16:18-26.

Dexter AR, Bird NRA. Methods for predicting the optimum and the range of water contents for tillage based on the water retention curve. Soil Till Res. 2001;57:203-12.

Dexter AR. Soil physical quality: Part I. Theory, effects of soil texture, density, and organic matter, and effects on root growth. Geoderma. 2004;120:201-14.

Dias TJ, Cavalcante LF, Leon MJ, Santos GP, Albuquerque RPF. Produção de maracujazeiro e resistência mecânica do solo com biofertilizante sob irrigação com águas salinas. Ci Agron. 2011;42:644-51.

Dourado Neto D, Nielsen DR, Hopmans JW, Reichardt K, Bacchi OOS, Lopes PP. Programa para confecção da curva de retenção de água no solo, modelo van Genuchten. Soil Water Retention Curve, SWRC (version 3.0 beta). Piracicaba: Universidade de São Paulo; 2001.

Ferreira MM. Caracterização física do solo. In: Jong van Lier Q, editor. Física do solo. Viçosa, MG: Sociedade Brasileira de Ciência do Solo; 2010. p.1-27. 
Fidalski J, Tormena CA, Scapim CA. Espacialização vertical e horizontal dos indicadores de qualidade para um Latossolo Vermelho cultivado com citros. R Bras Ci Solo. 2007;31:9-19.

Gee GW, Bauder JW. Particle-size analysis. In: Klute A, editor. Methods of soil analysis. $2^{\text {nd }}$.ed. Madison: American Society of Agronomy, Soil Science Society of America; 1986. Pt.1. p.383-411. (Agronomy monography, 9).

Hair Jr JF, Black WC, Babin BJ, Anderson RE, Tatham R. Análise multivariada de dados. $6^{\text {a }}$.ed. Porto Alegre: Bookman; 2009.

Hillel D. Introduction to environmental soil physics. San Diego: Elsevier Academic Press; 2004.

Ingaramo OE. Indicadores físicos de la degradación del suelo [tesis]. La Coruña: Universidad de La Coruña; 2003.

Kaiser HF. The varimax criterion for analytic rotation in factor analysis. Psychometrika. 1958;23:187-200.

Kiehl EJ. Manual de edafologia: Relações solo-planta. Piracicaba: Ceres; 1979.

Klein VA, Libardi PL. Condutividade hidráulica de um Latossolo Roxo, não saturado, sob diferentes sistemas de uso e manejo. Ci Rural. 2002;32:945-53.

Klute A. Water retention: Laboratory methods. In: Klute A, editor. Methods of soil analysis. $2^{\text {nd }}$.ed. Madison: American Society of Agronomy, Soil Science Society of America; 1986. Pt.1. p.635-62. (Agronomy monography, 9).

Libardi PL. Dinâmica da água no solo. São Paulo: Universidade de São Paulo; 2012.

Medeiros MB, Lopes JS. Biofertilizantes líquidos e sustentabilidade agrícola. Bahia Agríc. 2006;7:24-6.

Mota JCA, Assis Júnior RN, Amaro Filho J, Libardi PL. Algumas propriedades físicas e hídricas de três solos na Chapada do Apodi, RN, cultivados com melão. R Bras Ci Solo. 2008;32:49-58.

Mota JCA. Componentes do balanço de água em um Cambissolo cultivado com meloeiro irrigado por gotejamento, com e sem cobertura da superfície [tese]. Piracicaba: Escola Superior de Agricultura Luiz de Queiroz; 2010.

Mota JCA, Freire AG, Assis Júnior RN. Qualidade física de um Cambissolo sob sistemas de manejo. R Bras Ci Solo. 2013;37:1196-206.

Mota JCA, Alves CVO, Freire AG, Assis Júnior RN. Uni and multivariate analyses of soil physical quality indicators of a Cambisol from Apodi Plateau - CE, Brazil. Soil Till Res. 2014;140:66-73.

Neves CMNN, Silva MLN, Curi N, Cardoso EL, Macedo RLG, Ferreira MM, Souza FS. Atributos indicadores da qualidade do solo em sistema Agrossilvopastoril no noroeste do Estado de Minas Gerais. Sci For. 2007;74:45-53.

Nogueira FA. Influência da aplicação de um biofertilizante e matéria orgânica em algumas propriedades físicas de um Cambissolo da Chapada do Apodi-CE [dissertação]. Fortaleza: Universidade Federal do Ceará; 2009.
Pedrotti A, Mello Júnior AV. Avanços em Ciência do Solo: A física do solo na produção agrícola e qualidade ambiental. São Cristóvão: Universidade Federal de Sergipe; 2009.

Rühlmann J, Körschens M, Graefe J. A new approach to calculate the particle density of soils considering properties of the soil organic matter and the mineral matrix. Geoderma. 2006;30:272-83.

Silva AP, Kay BD, Perfect, E. Characterization of the least limiting water range. Soil Sci Soc Am J. 1994;58:1775-81.

Silva FL. Ambiência e biofertilização no cultivo orgânico de figo, em condições semiáridas [tese]. Fortaleza: Universidade Federal do Ceará; 2012.

Silva AP, Bruand A, Tormena CA, Silva EM, Santos GG, Giarola NFB, Guimarães RML, Marchão, RL, Klein VA. Indicators of soil physical quality: From simplicity to complexity. In: Teixeira WB, Ceddia MB, Ottoni MV, Donagemma GK, editors. Application of soil physics in environmental analyses. New Delhi: Springer; 2014. p.201-21.

Skoop JM. Physical properties of primary particles. In: Summer ME, editor. Handbook of soil science. Boca Raton: CRC Press; 2002. p.A1-A16.

Souza EJ, Cunha FF, Magalhães FF, Silva TR, Borges MCRZ, Roque CG. Métodos para estimativa da umidade do solo na capacidade de campo. R Ci Agro-Amb. 2013;11:43-50.

Stumpf L. Atributos físicos e mecânicos de um solo construído em área de mineração de carvão em Candiota-RS, cultivado com diferentes espécies [dissertação]. Pelotas: Universidade Federal de Pelotas; 2011.

Table Curve 2D. Table Curve 2D (Trial Version 5.01). [Accessed 2014 May 19]. Available at: http://www.sigmaplot.com/products/ tablecurve2d/tablecurve2d.php.

Tormena CA, Silva AP, Libardi PL. Caracterização do intervalo hídrico ótimo de um Latossolo Roxo sob plantio direto. R Bras Ci Solo. 1998;22:573-81.

United States Department of Agriculture - USDA. Natural Resources Conservation Service. Soil quality test kit guide. Washington: 1999.

van Genuchten MT. A closed-form equation for predicting the conductivity of unsaturated soils. Soil Sci Soc Am J. 1980;44:892-7.

Wilson MJ, Maliszewska-Kordybach B, editors. Soil quality, sustainable agriculture and environmental security in central and Eastern Europe. Dordrecht/Boston/London: Kluwer Academic Publishers; 2000. (NATO Science Series 2, Environmental Security, 69).

XLSTAT. Xlstat 2013 add-in for Excel (Trial Version). New York: 2013. [Accessed 2014 Mar 25]. Available at: http://www. xlstat.com.

Yeomans JC, Bremner JM. A rapid and precise method for routine determination of organic carbon in soil. Commun Soil Sci Plant Anal. 1988;19:1467-76. 